\title{
INFLUJOS INSTITUCIONISTAS: LA INSTITUCIÓN LIBRE DE ENSEÑANZA Y LA PATRIMONIALIZACIÓN DEL PAISAJE EN LA PINTURA VALENCIANA DEL SIGLO XIX
}

\author{
Mari Carmen Hernández Perelló \\ Museo Sorolla
}

\begin{abstract}
Resumen: El presente trabajo pretende profundizar en el estudio de la pintura paisajística realizada en la zona valenciana a finales del siglo XIX. Para ello se analiza la influencia ejercida por la Institución Libre de Enseñanza en ciertos artistas que seleccionaban, para representar, lugares cercanos, paisajes que les pertenecían pero a los que ellos también pertenecían.
\end{abstract}

Palabras clave: pintura paisajística, zona valenciana, Institución Libre de Enseñanza, pintores.

Influxes of Institución Libre de Enseñanza: the landscape patrimonialization in the valencian painting of the nineteenth century

Abstract: This paper aims to deepen the study of landscape painting done in the Valencia area in the late nineteenth century. For this, the influence exerted by the Institución Libre de Enseñanza in certain artists who selected to represent nearby places, landscapes that belong to them but to which they belonged, is also discussed.

Key words: landscape painting, Valencia area, Institución Libre de Enseñanza, painters.

\section{INTRODUCCIÓN}

La mirada a la naturaleza con nuevas inquietudes y mayor fidelidad se percibe tanto en la pintura de paisaje como en otros géneros a partir de 1850.

Como señala Pérez Rojas "La concepción del paisaje pictórico como reflejo de una realidad geográfica que define y condiciona la personalidad de los pueblos, el tipo de vida de sus moradores y hasta su carácter es un pensamiento que se desarrolla en gran medida a mediados del siglo XIX con el realismo y la difusión del pensamiento positivista, pero que se consolida en las décadas finales del siglo reforzado por actitudes como la de la Institución Libre de Enseñanza (...)" (Pérez Rojas, 1998, 57).

En Valencia, a finales del siglo XIX se produjo un importante desarrollo de la pintura de paisaje, aunque "no sería hasta los años 70 cuando la prensa valenciana se hiciera eco de los ejercicios al aire libre" (López Albert, 2007, 149).

En líneas generales, el avance experimentado por la pintura valenciana de paisaje se debió, por un lado, a la implantación de los nuevos planteamientos pictóricos que llegaron desde Madrid. Fue fundamental el papel del pintor Carlos de Haes que rompió con el paisaje romántico e inició la pintura de paisaje realista en España. Pero por otro lado, también fue fundamental la llegada del institucionismo a Valencia.

Data de recepció: 8 de setembre de 2016 / Data d'acceptació: 25 de setembre de 2016. 


\section{LA INSTITUCIÓN LIBRE DE ENSEÑANZA EN VALENCIA}

La Institución Libre de Enseñanza no sólo tuvo un papel importante en Madrid, sino que su influencia se extendió a otros lugares, entre ellos, Valencia.

A finales del siglo XIX, algunos intelectuales institucionistas llegaron a Valencia: Eduardo Pérez Pujol; un único valenciano Eduardo Soler y Pérez; José Villó y Ruiz; Alfredo Calderón y Arana; y Aniceto Sela y Sampil (Esteban, 1974, 120). De esta forma el pensamiento institucionista se difundió por la zona valenciana y quedó reflejado en múltiples ámbitos: universitario, jurídico, literario, artístico, etc.

El institucionismo valenciano se conformó en torno a una serie de cuestiones básicas que le dieron cohesión. El principal nexo de unión del grupo fue la adscripción a la filosofía krausista, tanto a nivel jurídico como sociológico. Los institucionistas valencianos tenían como principal objetivo la regeneración de la sociedad a través de la educación. Su pretensión no quedaba reducida sólo a enseñar e instruir, sino a educar.

También prestó especial atención al tema del trabajo y la educación de la mujer. Además el amor a la naturaleza fue otra característica común en todos los institucionistas. La Naturaleza había sido divinizada por los krausistas en su mística religiosa, por lo que tenía que ser ennoblecida, convertida en templo para albergar las obras del Creador. Los componentes del grupo valenciano, especialmente Soler, Sela y Calderón, hicieron derivar este principio natural hacia una concepción educativa que, rompiendo el ámbito del aula, tomó contacto con la vida a través de la práctica de excursiones. Estas salidas no eran un mero pasatiempo sino que suponían un tipo de enseñanza unida a la experiencia activa.

Pero el grupo institucionista inicial se fue ampliando con la llegada de otros intelectuales afines a la Universitat de València y a la ciudad. Muchos de ellos se implicaron en la creación de instituciones educativas encaminadas al gran objetivo institucionista, la regeneración social, como: la Escuela de Artesanos, la Escuela de Comercio para Señoras, la Institución para la Enseñanza de la Mujer, Extensión Universitaria, la Universidad Popular, etc. Entre los continuadores del institucionismo en Valencia cabe destacar a Eduardo Boscà; Rafael Altamira y Crevea; José Deleito y Piñuela; José Navarro Alcácer; Angelina Carnicer Pascual; Luis Morote y Greus; Adolfo González Posada; Luis Simarro Lacabra, etc.

A nivel cultural y, especialmente, relacionado con la naturaleza y la nueva visión de ésta propugnada por la Institución Libre de Enseñanza, su influencia se tradujo en la realización de estudios geográficos, interés por el excursionismo, auge de la literatura de viajes y desarrollo de la pintura de paisaje.

Las descripciones geográficas del momento se basaban en observaciones directas del terreno, ayudadas por documentación exhaustiva y el estudio de mapas, fotografías, planos y libros. Por su parte, la realización de excursiones partió de entidades como la Institución para la Enseñanza de la Mujer, la Facultad de Medicina, la Facultad de Derecho o la de Ciencias, todas ellas vinculadas al institucionismo. Estas salidas eran una práctica habitual debido al valor educativo que otorgaban al contacto con la naturaleza. Ortega Cantero explica que "Esta dimensión regeneracionista que se atribuye al conocimiento geográfico se encuentra reiteradamente presente, por ejemplo, en los enfoques y en las recomendaciones de Rafael Torres Campos, institucionista, geógrafo y profesor de la Escuela Normal Central de Maestras. En uno de sus escritos, dedicado a la Enseñanza superior de la Geografía, recuerda Torres Campos la utilidad del conocimiento geográfico tanto en el ámbito científico y cultural, como en el terreno militar y comercial" (Ortega Cantero, 1986, 88). 
De este afecto por la naturaleza, el paisaje, la geografía y las excursiones también derivó un importante incremento en la publicación de literatura de viajes. Eduardo Soler fue uno de los institucionistas más prolijos en este género literario; en su Viaje por Aitana (1893), realizó una breve interpretación de esta sierra alicantina, en la que contrapuso sus características con las de otros tipos paisajísticos como la huerta. También se debe señalar la labor desarrollada por Rafael Altamira, que acompañaba a Soler en sus excursiones por la provincia y recopiló todas estas salidas en su obra Ideario Pedagógico (1923).

Toda esta cultura de índole institucionista desarrollada en torno a la naturaleza, tendrá un papel muy importante en el inicial interés, y posterior desarrollo de la pintura valenciana de paisaje de finales del siglo XIX.

Los institucionistas valencianos también participaron en entidades culturales como el Ateneo Mercantil y la Real Sociedad Económica de Amigos del País en Valencia. Precisamente, estas dos entidades tenían una importante actividad de promoción de las artes ya que organizaban debates, conferencias, discursos, etc, a la vez que realizaban la mayoría de Exposiciones de Bellas Artes celebradas en Valencia y encargaban obras artísticas para sus sedes.

Además es fundamental recordar el paso de diversos artistas del momento (Sorolla, Gonzalo Salvà, Pinazo, etc.) por centros de importante calado krausista e institucionista como la Escuela de Artesanos (Hernández Perelló, 2015, 553-554). De hecho la Escuela de Artesanos impartía enseñanzas artísticas y, precisamente, entre las predilectas de los alumnos se encontraban las asignaturas de dibujo y paisaje.

\section{INFLUJOS INSTITUCIONISTAS EN LA PINTURA VALENCIANA DE PAISAJE}

El institucionismo fue uno de los motivos por los que la pintura de paisaje experimentó un importante desarrollo en la zona valenciana, y esto se observa de forma evidente en algunas de las características que presenta este género pictórico desarrollado en la zona. Aunque la pintura de paisaje valenciana de estos momentos presenta su propio carácter, es innegable la influencia que ejerció en ella el ideario de la Institución Libre de Enseñanza (Hernández Perelló, 2015, 487).

En sí, el interés surgido por la naturaleza y el consecuente desarrollo del género paisajístico es ya una cuestión característica de la ILE, pero además, en ella se compendian el resto de teorías institucionistas sobre naturaleza y paisaje.

Una de las cuestiones fundamentales que se puede observar en la pintura valenciana de paisaje y que es una clara influencia de la ILE, es la elección de los lugares representados. En estos momentos se escogen para su representación lugares cercanos, familiares, espacios que conforman parte del entorno y por tanto, y de alguna manera, de la vida del artista, aunque también tenían en cuenta que fueran conocidos para el público. Algunos artistas retratan las zonas más cercanas a su pueblo natal o bien los alrededores de los sitios donde van a pasar la temporada estival. Así pues, durante los años de formación, los paisajistas valencianos buscaron en la geografía local lugares emblemáticos y atractivos. Esta representación de lugares geográficos concretos, es una de las mayores diferencias con respecto a la pintura de paisaje anterior. El artista, con este acercamiento al paisaje autóctono, busca plasmar en la obra una parte de sí mismo y además una mayor conexión con el público. 
El pintor Carlos de Haes fue el promotor del excursionismo para la representación realista de lugares, pero la figura que verdaderamente hace del excursionismo un auténtico método pictórico fue el institucionista Aureliano de Beruete. Pues bien, aunque existía una importante relación entre las Academias de Madrid, donde Carlos de Haes era catedrático de Paisaje, y Valencia, y en esta última ya se empieza a salir al exterior en 1872, creemos, por lo importante que fue el institucionismo en la zona y la importancia que adquirió el excursionismo, que la ILE tuvo también mucho que ver en las excursiones que realizaban los artistas valencianos porque éstas no son una mera salida para realizar una representación del natural, sino que van cargadas de muchas otras connotaciones relacionadas con los preceptos institucionistas.

Los pintores realizaban excursiones de manera individual, eligiendo los lugares que representarían en sus obras, pero diversas instituciones también promovían el excursionismo, como es el caso del Círculo de Bellas Artes. Roig Condomina escribe "A finals de maig de 1895, en junta general, es verificà la primera renovació de la directiva. Igualment s'anomenaren els individus que havien de responsabilitzarse de les quatre seccions en qué s'havia dividir la societat: d'Exposicions, de Classe, de Revetles i Festes, i d'Excursions"' (Roig Condomina, 1996-1997, 239).

Todo este excursionismo y elección de lugares, está relacionado con otra característica fundamental del institucionismo, la visión dual de la naturaleza, heredera de la geografía moderna. La ILE defendía una visión dual de la naturaleza, es decir, una visión observadora (objetiva y científica) y otra más contemplativa (subjetiva y estética) en la que tiene mayor protagonismo el sujeto. En el caso de la pintura de paisaje valenciana, por un lado y relacionado con la parte objetiva, el artista representa con total fidelidad los lugares seleccionados. Por otro lado, y más relacionado con la parte subjetiva, encontramos que el artista selecciona lugares que para él significan algo e influye en el modo de representarlos todo aquello que el lugar supone para el pintor. Por primera vez, esta pintura expresa ese gusto por la contemplación que exige el género y en la que hasta entonces no se había encontrado interés alguno.

Desde el punto de vista objetivo, esta pintura, pasó de no diferenciar los elementos que formaban parte del paisaje representado, a utilizar un gran detallismo y una mayor fidelidad al natural. De esta manera, existen algunas obras en las que se pueden advertir lugares concretos y diferenciar las especies vegetales representadas. Según López Albert, "Los árboles siempre verdes y frondosos (...) desaparecieron de las telas, dejando paso a parajes concretos, a montañas con nombres y apellidos y a lugares reconocibles por el ciudadano de a pie" (López Albert, 2008, 106).

En lo referido a la visión subjetiva, ésta va unida a la cercanía de los paisajes representados. Como ya hemos visto, solían ser paisajes próximos, de tal manera que despertaban en el artista una serie de sentimientos relacionados con todos aquellos recuerdos, vivencias, etc., que les confería el lugar. Había interés en que el paisaje transmitiera un mensaje y los pintores buscaron varias opciones, entre ellas escoger un lugar conocido del público, lo que provocaba que en cada espectador surgiera un pensamiento o un sentimiento en torno al paisaje representado.

La ILE creía que el acercamiento y el conocimiento de la naturaleza era capaz de despertar en los españoles la conciencia nacional. Este aspecto es también evidente en la pintura de paisaje que se desarrolla en Valencia, no en lo que se refiere estrictamente a la conciencia nacional, sino que en este caso el paisaje representado se convierte en un símbolo, en una manifestación por parte del artista, de pertenencia a un lugar determinado. 
Por todo esto la pintura valenciana de paisaje se fue renovando, se eliminaron los objetos que restaban protagonismo a la naturaleza y se fue dando una mayor presencia a cielos, vegetación, mares, montañas, etc. Pero lo que en ocasiones, los pintores valencianos no fueron capaces de eliminar fue la representación de ciertos elementos arquitectónicos (fortalezas, ruinas medievales, monasterios, conventos, etc.), que se convirtieron en algunos de los pocos elementos que se representaban en el paisaje. Existen en Valencia dos elementos que fueron especialmente representados por los artistas: la Cartuja de Porta Coeli y la Cartuja de Vall de Crist. Este aspecto también presenta similitudes con la ILE, que sintió auténtica predilección por la Cartuja del Paular en la Sierra de Peñalara. Estos elementos eran considerados testimonios históricos de la Época Medieval por lo que, al igual que la ILE, otorgaban una gran importancia a esta época ya que durante este período la zona valenciana experimentó un importante desarrollo. En general, había un grupo de temas predilectos para los paisajistas, los castillos, por ejemplo, estaban en clara desventaja frente a los monasterios, asiduos protagonistas de los cuadros del paisaje. Esta circunstancia llama aún más la atención si tenemos en cuenta que las diversas comarcas valencianas poseían un considerable número de fortalezas.

De manera directa o indirecta, está claro que las teorías institucionistas sobre la naturaleza y el paisaje quedaron reflejadas en el carácter de la pintura de paisaje que se creó en la región valenciana a finales del siglo XIX, y esto es debido a la llegada y difusión del institucionismo por la ciudad de Valencia en particular, y por la zona valenciana en general.

\section{LA MONTAÑA COMO PROTAGONISTA EN LA PINTURA VALENCIANA}

En los años noventa del siglo XIX los pintores paisajistas valencianos se especializaron en diferentes realidades geográficas como el mar, la huerta, la montaña, los valles, etc.

El enfoque de la primera pintura de paisaje realista que se realiza en Valencia no rompe los moldes clásicos, pese a que la factura suelta resultaba muy moderna. Pero la pintura de paisaje de los años 80 y 90 del XIX ya aúna una técnica y unas connotaciones más modernas, que desde nuestro punto de vista la sitúan al mismo nivel de la pintura de este género que se estaba realizando en Europa.

La necesidad de mantener contacto con la naturaleza surgida en el Romanticismo tuvo como consecuencia que los pintores se fijaran en aquellos paisajes que para ellos eran más cercanos. "Así, los madrileños representaban El Pardo, la Casa de Campo, la Sierra de Guadarrama; los catalanes el bosque de Olot; los del norte se centraron en la ría de Pravia, el Nalón o los Picos de Europa y los andaluces en los paisajes alrededor del río Guadalquivir, Granada y la zona de Alcalá de Guadaira” (López Albert, 2008, 106).

Por su parte, los paisajistas valencianos buscaron aquellos lugares que les resultaban emblemáticos, sacándolos de la cotidianeidad para representarlos en el lienzo. De esta manera la geografía valenciana entró a formar parte del repertorio de los paisajistas del mismo modo que sucedió en el resto del país.

Pero es importante destacar la especial atención que recibió la montaña. Gracias a la ILE se produjo una revalorización de este tipo de paisaje y es una de las cuestiones que también se refleja en la pintura valenciana de paisaje. Aunque en ocasiones no se puede conocer con seguridad qué motivó a los artistas en la elección de un determinado paisaje montañoso, la mayoría de veces dicha elección está relacionada con la idea de pertenencia a un lugar. Es en este modo de utilizar el tema de la montaña donde más se observa la in- 
fluencia de la ILE. Sierras, valles, barrancos, desfiladeros, cascadas, se convirtieron en los grandes protagonistas de las obras.

De la geografía valenciana, los lugares montañosos representados con más frecuencia fueron la Sierra de Corbera (Valle de la Murta, Sierra de las Agujas); la Sierra Calderona; el Valle de Aguas Vivas; la Sierra del Negrete y la Sierra del Menejador. Todos estos lugares resultaron muy atrayentes para artistas y curiosos visitantes, por ello es interesante analizar qué artistas los representaron y la manera de representarlos.

\section{Sierra de Corbera}

Localizado en la Sierra de Corbera, uno de los valles que más interés despertó en los artistas valencianos fue el Valle de la Murta en Alzira (Valencia). Este lugar no sólo destaca por su interés paisajístico sino por su valor botánico, ya que cuenta con gran cantidad de especies vegetales. Su situación privilegiada lo convirtió en un lugar de recogimiento por lo que se levantó un monasterio jerónimo, el de Santa María de la Murta, construido entre el siglo XIV y XV. Pero con la desamortización de Mendizábal en 1836, quedó abandonado y en estado de ruina. Fue precisamente ese estado, unido al entorno natural en el que se encuentra, lo que despertó la atención de viajeros, pintores y escritores en el siglo XIX (Delicado Martínez; Ballester Hernán, 1999, 80).

Fueron varios los artistas que se interesaron por este lugar y decidieron dejarlo plasmado en algunas de sus obras. Es el caso de Rafael Montesinos Ramiro (1811-1877). Aunque romántico, es interesante hacer referencia a este pintor y a sus obras sobre la Murta porque ejerció una importante influencia en los artistas y la pintura de paisaje posterior. En la Exposición Nacional de 1864 ya presentó, junto a otras obras, Puente de entrada al destruido Monasterio de la Murta. Sentía especial predilección por la zona de Alzira, de ahí que en muchas de sus obras representara el paisaje del Valle de la Murta: El Monasterio de la Murta (1846), El Monasterio jerónimo de la Murta (1846), La Murta. Puerta del Monasterio (1855) y Puente de entrada al destruido monasterio de la Murta (1864). Es por ello, que puede ser considerado el introductor de los paisajes de la Murta en la pintura de este género en Valencia.

Antonio Muñoz Degrain (1840-1924) también representó el lugar, aunque ya con un mayor realismo y fidelidad. Como indica Bonet Solves “(...) la paleta del pintor le sitúa en los puestos avanzados del paisaje moderno. Su tratamiento de los tonos podría aproximarlo a las osadías impresionistas por el impacto visual del conjunto, al igual que ese interés por experimentar toques. Pero el resultado final es muy diferente; la solución de sus obras encierra una prudencia demasiado significativa" (Bonet Solves, 1994, 263). Cronológicamente tampoco está dentro del período que nos interesa, pero tuvo un papel fundamental en el paisajismo valenciano e influyó directamente en pintores posteriores.

Degrain, por influencia de su maestro, Rafael Montesinos Ramiro, también realizó obras sobre la Sierra de Corbera como Sierra de las Agujas, tomada desde la loma del Cavall-Vernat (1864) (Fig. 1), Paisaje con castillo/monasterio (1870) (Fig. 2) o El Tallat Roig (1874). En el primero de estos se compendian algunas características que el pintor desarrollará a lo largo de su producción artística. Muestra su preferencia por los paisajes montañosos al elegir un paraje agreste de la geografía valenciana. Además también apreciamos la elección de un punto de vista alto para la composición, obteniendo como resultado una visión panorámica mucho más narrativa. También en la Exposición Nacional de Bellas Artes de 1864 obtuvo una tercera medalla por su cuadro Vista del valle de la Murta (Alzira). 


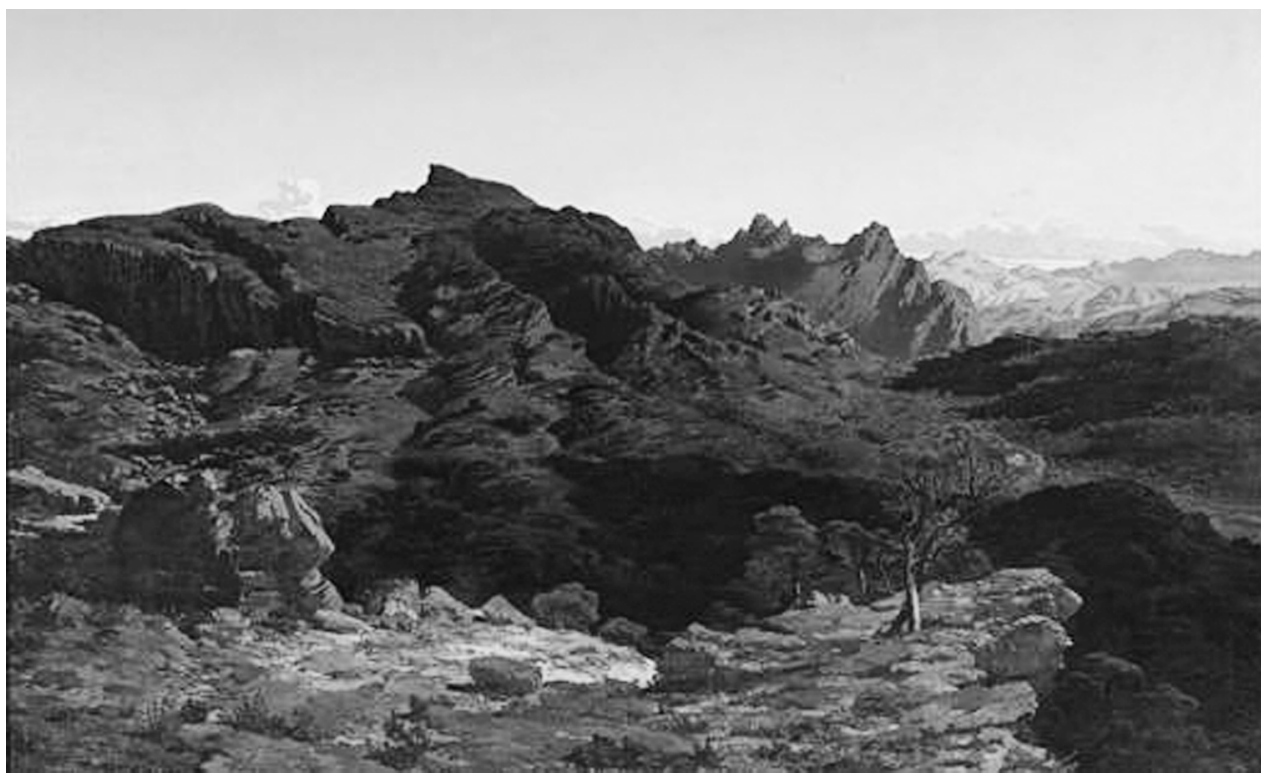

Fig. 1. Antonio Muñoz Degrain, Sierra de las Agujas, tomada desde la loma del Cavall-Vernat, 1864. Óleo sobre lienzo, 144 x $217 \mathrm{~cm}$. Museo del Prado, Madrid.

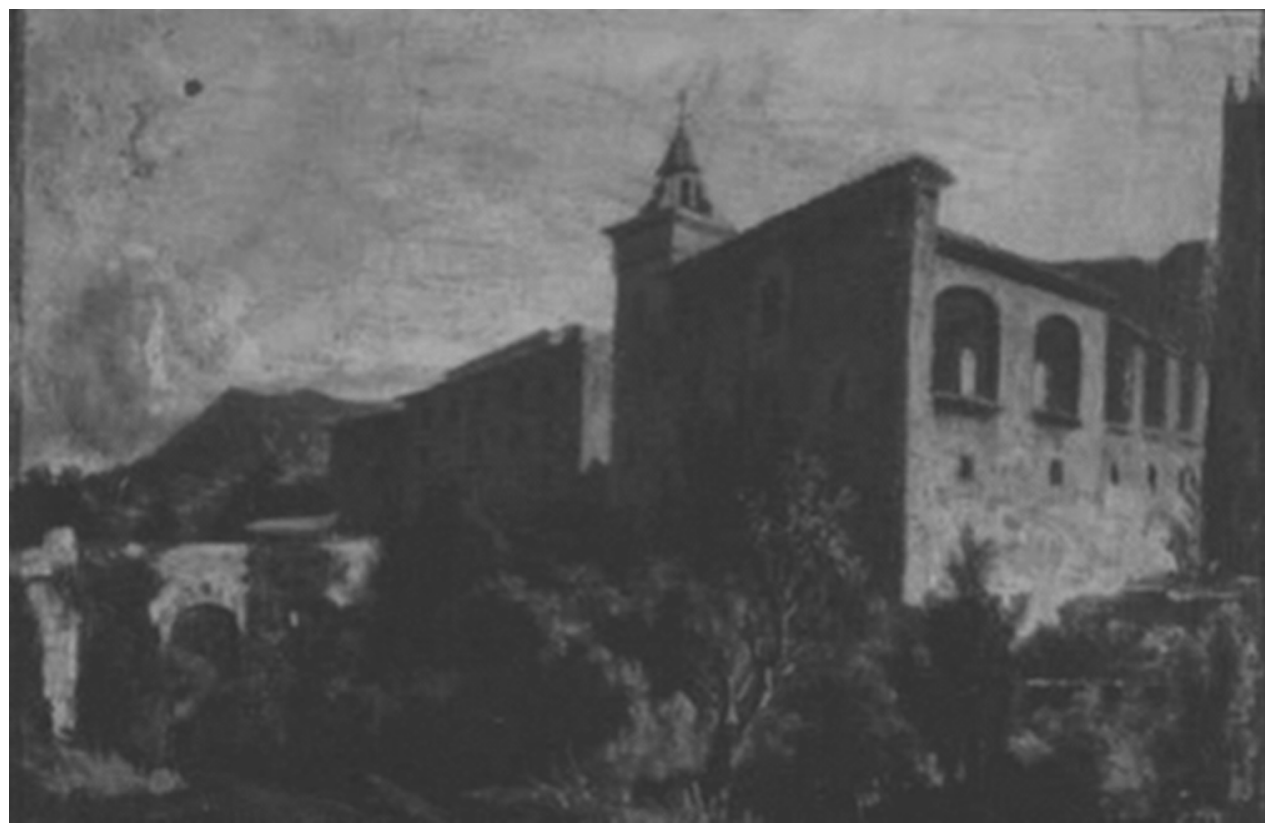

Fig. 2. Antonio Muñoz Degrain, Paisaje con castillo/Monasterio, 1870. Óleo sobre lienzo, 38 x $25 \mathrm{~cm}$. Museo de Bellas Artes San Pío V, Valencia. 
Como se puede observar Degrain elegía para representar lugares concretos y a pesar de la influencia que se observa en sus paisajes de sus maestros, Rafael Montesinos y Carlos de Haes, una influencia fundamental fue la de Giner de los Ríos y el institucionismo, “Giner de los Ríos, en 1885 volvía, como los románticos, a entender el paisaje desde los sentidos, no describirlo tanto desde lo visto como de lo sentido" (Sauret, 2007, 44). Muñoz Degrain debe ser considerado como uno de los descubridores del paisaje de alta montaña valenciano.

Otro de los artistas que dedicó algunas de sus obras a la Sierra de Corbera fue Rafael Montesinos Ausina (1859-1924), prestando especial interés al Valle de la Murta y a su monasterio. Heredó tanto de su padre como de su maestro, Antonio Muñoz Degrain, el interés por la pintura de género paisajístico. En 1871 remitió a la Exposición Nacional de Bellas Artes las obras Barranco negro en Alzira y Estrecho camino a la Murta. Con obras como Estrecho camino de la Murta (1871), Valle de Corbera (1874) o El Valle de la Murta (1883), mostró su interés por esta zona emblemática de la geografía valenciana, resaltando el aspecto natural del paisaje. La última de las obras la presentó a la Exposición Regional Valenciana de 1883 organizada por la Real Sociedad Económica de Amigos del País. En sus paisajes sigue la tendencia naturalista del momento pero aporta a la representación del lugar escogido su propio punto de vista. Estos dos aspectos (objetividad-subjetividad) unidos a la hora de la representación suponen una herencia de las teorías de la ILE que a su vez recogió del pensamiento krausista.

Rafael Monleón y Torres (1843-1900) es un artista poco conocido como pintor de montañas, ya que destaca como excelente pintor de marinas. Pero en la tipología de montañas podemos citar Varias vistas del Barranco de la Murta que presentó en la Exposición Regional Valenciana de 1867. Están en paradero desconocido, pero se sabe que con ellas se ganó el favor de la crítica. Como discípulo que fue de Haes, en sus obras se observa la obsesión por la fidelidad al modelo.

Esta sierra también fue de interés para Javier Juste (1856-1899). Aunque su predilección también eran las marinas, en 1884 presentó a la Exposición Nacional de Bellas Artes varias obras, entre ellas El Monasterio de la Murta. El tamaño ya no es reducido, sino que ya es de mayores dimensiones $(1,47 \mathrm{~m}$ x $0,88 \mathrm{~m})$. En la prensa del momento se califica este cuadro como "risueño, fresco y sumamente pintoresco". En los primeros años utilizó colores luminosos, mientras que en su obra más avanzada se decantó por unas tonalidades grises y, a su vez, por un estilo más fantástico y menos naturalista. Pero si algo se mantiene común en toda su obra, es la factura minuciosa. Es autor de un paisaje descriptivo con refinadas composiciones, fruto de su vagar por campos y parajes, de una directa relación con la naturaleza en excursiones, que ya posibilitaban los nuevos medios de transporte.

José Vilar y Torres (1828-1904) sintió especial inclinación por los paisajes montañosos. Fue otro de los artistas que se interesó por el paisaje del Valle de la Murta, que dejó reflejado en su obra Recuerdo de la Murta. Presentó esta obra a la Exposición celebrada en el Ateneo Valenciano en 1885, por la que fue premiado con una medalla. A nivel formal, le da mucha importancia al dibujo y sus obras siempre estaban muy acabadas. En sus pinturas es evidente la influencia de Carlos de Haes, sobre todo, en lo relacionado con la observación directa de la naturaleza. Vilar elimina de sus pinturas paisajísticas la figura humana, en ellas el protagonismo recae en la propia naturaleza. En aquellas en las que sí aparece alguna figura, ésta solamente tiene carácter anecdótico o decorativo. En este artista se puede adivinar cierto regeneracionismo institucionista, ya que consideraba que las 
Bellas Artes tenían una importante influencia en la educación de la sociedad. También de la ILE procede su interés por el excursionismo, gracias al cual descubrió lugares como la zona cantábrica o los Picos de Europa.

Pero como hemos dicho anteriormente, no sólo la Sierra de Corbera y en concreto, el Valle de la Murta, despertaron el interés de estos artistas valencianos, sino que otras zonas de la geografía valenciana, destacables por su carácter montañoso, también fueron objeto de representación por parte de estos. Era una cuestión no sólo de estética, sino además de afinidad y los artistas representaban aquellos lugares que despertaban algún sentimiento pero que, a la vez, sentían como cercanos.

\section{Sierra Calderona}

Otro lugar por el que la pintura de estos años se interesa mucho fue la Sierra Calderona, declarada Parque Natural en 2002, y situada entre la provincia de Castellón y Valencia. En esta sierra un lugar muy apreciado por los pintores valencianos fue la zona de los Montes de Portacoeli, localizada en el interior del término municipal de Serra. Es un lugar al que a lo largo de los años han llegado excursionistas, artistas y curiosos.

En estos montes, un elemento muy representado ha sido la Cartuja de Porta Coeli, monasterio cartujo situado en el Valle de Lullén, fundado por el dominico Fray Andrés de Albalat en 1272. Fue la primera cartuja construida en el Reino de Valencia y la tercera de la Corona de Aragón. Con la desamortización, fue exclaustrada y subastada, al igual que todos sus dominios. Y tras pasar por varios propietarios, en 1943 la Diputación Provincial la compró y en 1944 regresaron a ella los monjes cartujos.

Este lugar ha sido muy representado en la plástica valenciana del XIX. Francisco Jesús Reguera (1852-1887) en la Exposición Nacional celebrada en Valencia de 1883 presentó entre otras, Un paisaje muy solitario de montaña, que representa la zona de los Montes de Porta Coeli. Un año después realizó la obra Alrededores de Portacoeli (1884) que presentó a la Exposición Nacional de ese mismo año. El tema principal es la naturaleza en sí misma, aunque aparecen algunos animales que tienen un simple papel decorativo. La escasa información sobre esta obra proviene de la prensa del momento, por ejemplo el día 17 de abril de 1884, aparecía en el Diario Las Provincias una descripción de esta obra "En primer término hay una pradera llena de flores, cuyo abigarramiento de matices traduce el artista por medio de pinceladas sueltas. Entre la yerba corre una bandada de polluelos de perdiz, porque ven al gavilán que baja sobre ellas. El fondo de montañas es muy bonito”.

El pintor Ramón Stolz Seguí (1872-1924) aunque cultivó diversos géneros, destacó como paisajista y pintor de flores. Se interesó por distintos lugares de la geografía de Valencia, entre los que se pueden encontrar diferentes pinturas de montaña, obras en las que destaca su gusto por las zonas escarpadas y los detalles rocosos. Stolz Seguí quedó cautivado por lugares como el Valle de Porta Coeli y es por ello que lo representa en su obra Cercanías de Porta Coeli (1892), que presentó a la Exposición Internacional de Madrid de 1892.

Aunque escasamente conocido, Salvador Ferrer Calatayud, hermano y discípulo del pintor marinista Pedro Ferrer Calatayud, presentó a la Exposición Nacional de Bellas Artes de 1897 el cuadro Barranco de Serra, donde representa los alrededores de Serra.

Por su parte Constantino Gómez Salvador (1864-1937) se interesó también de forma especial por el paisaje. Sus obras eran estudios minuciosos de la naturaleza con una gran 
riqueza de colorido. En la Exposición Internacional de 1892 presentó dos paisajes, uno de ellos era Paisaje de Porta Coeli.

El pintor José Ortiz de Gamundi (1862-1940) también participó en la Exposición Internacional de 1892 celebrada en Madrid, con un paisaje titulado Porta Coeli. Diversos autores coinciden en recordarlo como modesto pintor de paisajes y pintor escenógrafo.

El conjunto paisajístico de la Sierra Calderona también rodea el Monasterio franciscano del Santo Espíritu que se encuentra localizado en el Valle de Tolíu. Doña María de Luna, esposa del rey de Valencia, Martín IV, donó las tierras a los franciscanos. Tras la desamortización, no fue adquirido pero a pesar de esto, no sufrió deterioros, ya que había un grupo de monjes que se encargaba de su mantenimiento. En 1878 fue restaurado siendo sede de la Curia Provincial hasta 1910, que pasó a Valencia.

Este monasterio ha sido muy importante en la cultura valenciana, algo que se puede observar a finales del XIX con la visita de excursionistas y pintores, "Además de que la zona ofrecía una riqueza natural especial en el territorio valenciano, los artistas que se fijaron en ella se caracterizaron por trasladar pulcramente al lienzo los diferentes elementos" (López Albert, 2008, 113).

Javier Juste pintó la obra Convento del Santo Espíritu del Monte en una tarde de invierno, que presentó a la Exposición Nacional de 1884. Aunque en la actualidad esta pintura no se conserva, existen descripciones de ella, motivo por el cual sabemos que, aunque el tema principal es la propia naturaleza, el artista se muestra más conservador y no representa un paisaje puro sino que en él inserta figuras de tamaño muy reducido. Siguiendo la tendencia del momento, representa con gran fidelidad el entorno, tanto la vegetación como la morfología de las rocas. Aparecen vertientes pedregosas en un día nublado y triste, y también se puede observar la presencia de un fraile y un burro.

De igual forma, José Vilar y Torres realizó la obra desaparecida Paisaje del Sancto Spiritu, que se cree que presentó a la Exposición Internacional de 1887. Otra de las obras de Vilar y Torres sobre esta zona es Paisaje con montaña también de 1887. Pese a que esta obra se encuentra en paradero desconocido, podría coincidir con el cuadro hallado en una casa de subastas (Fig. 3), ya que existen muchas coincidencias. Ésta, evidencia la predilección que sentía el artista por los paisajes montañosos. En la lejanía aparece representada una arquitectura que corresponde al Monasterio del Santo Espíritu, pero el protagonista es el paisaje. El edificio se camufla entre la vegetación y la montaña. A nivel formal es de destacar el dibujo, que es totalmente detallista, consiguiendo una representación objetiva y totalmente fiel tanto de la vegetación como de la morfología del terreno. Aunque también es de destacar el color, sobre todo en la combinación que hace de tonos ocres y verdes en la vegetación, que le otorgan un gran realismo. Desde el punto de vista compositivo, se pueden destacar cuatro planos principales. Un primer plano hasta el centro de la obra, en el que el espacio es ocupado por la vegetación; el segundo, en el que representa el monasterio; el tercero, en el que la montaña parece reivindicar cierto protagonismo y el último plano, que sería el celaje. Para obtener una obra de este tipo es necesaria la observación directa del natural, lo cual corrobora que el pintor era un apasionado del excursionismo.

Otro pintor paisajista del momento fue Enrique Saborit (1869-1928). Para algunos críticos del momento, los paisajes de gran formato de este artista destacaban por su tono melancólico y triste. Saborit también se interesó por el paisaje del que estamos hablando y presentó a la Exposición Universal de Barcelona de 1888 un Paisaje del Santo Spiritu. 


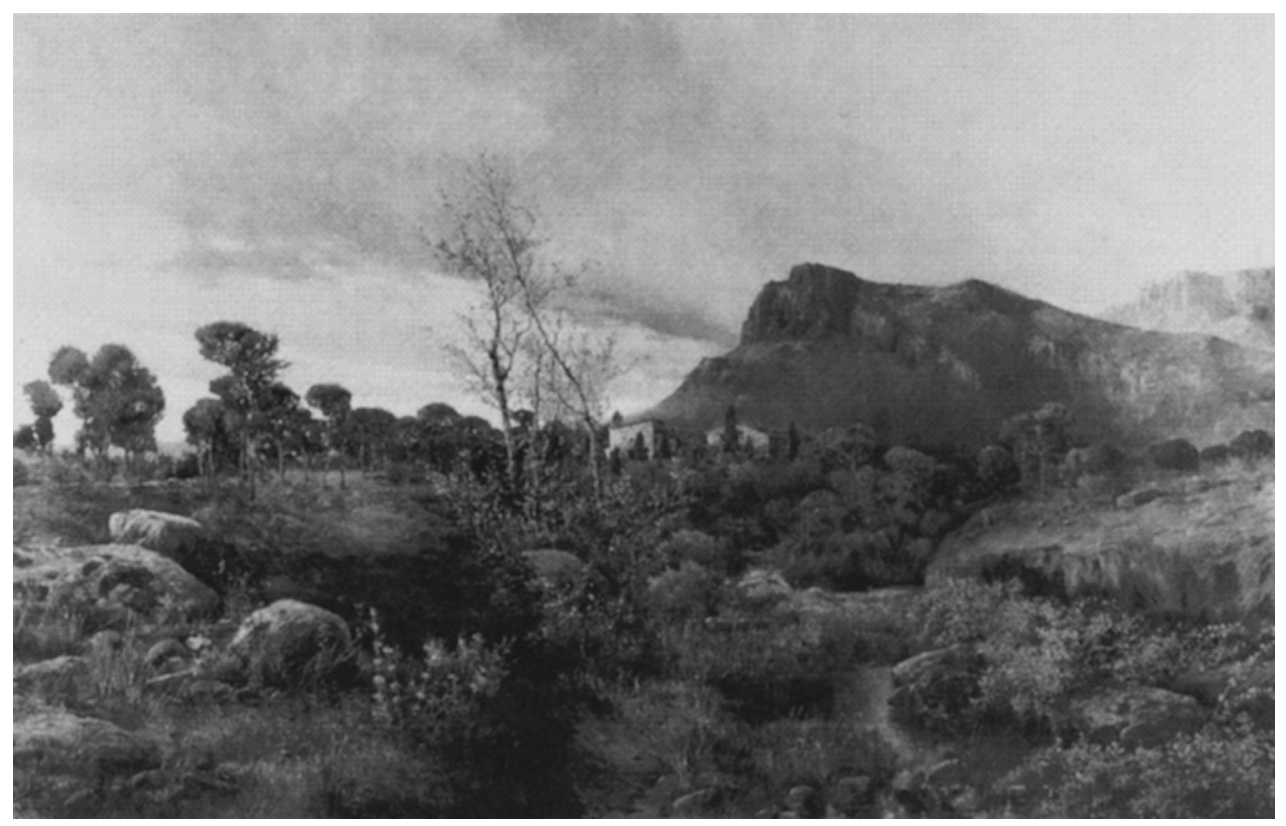

Fig. 3. José Vilar y Torres, Paisaje con montaña, 1887. Óleo sobre lienzo, 196 x 345 cm. Colección Particular.

Mientras, el pintor valenciano Francisco Mas y Carrasco presentó como primer trabajo público, Un país, a la Exposición celebrada en el Ateneo Casino de Valencia de 1881. Posteriormente expuso otros paisajes en comercios de la ciudad y en 1882 se sabe que realizó una obra sobre este lugar.

\section{Valle de Aguas Vivas}

El valle de Aguas Vivas se abre en Alzira para concluir a la entrada de la Valldigna, en lo alto del Portichol. En la ladera recayente a Carcaixent, se alza el Convento de los Agustinos de Aguas Vivas, cuya primera noticia escrita data de 1243, cuando Alzira fue ocupada por Jaime I.

Sobre este lugar Rafael Montesinos Ramiro hizo su obra Convento de Aguas Vivas cerca de Carcagente realizada en 1844. Esta obra junto con otras presentadas anteriormente, muestran el interés del artista por su entorno natural.

Javier Juste también se interesó por este lugar y realizó la obra Vista de Aguas Vivas, presentada a la Exposición que se organizó en Valencia en 1885 para la Feria de Julio de ese mismo año. 


\section{Sierra del Negrete}

La Sierra del Negrete es una zona montañosa con más 30 km de extensión. Uno de los artistas que más se interesó por la representación de esta sierra fue Gonzalo Salvà. Éste fue un pintor de grandes aptitudes para todos los géneros, pero cultivó con preferencia el paisaje. Gonzalo Salvà fue el introductor en Valencia, de las fórmulas implantadas por Carlos de Haes en la Real Academia de Bellas Artes de San Fernando en Madrid (interés por la pintura de paisaje, estudio del natural mediante la realización de excursiones, análisis de detalles, cuidada composición, etc.). Salvà realizaba excursiones a los alrededores de Valencia, centrando su interés en las montañas. Los estudios que realizaba de la Naturaleza eran muy exhaustivos, y reflejaba en sus obras todos los detalles. Sus lienzos suelen mostrar un sitio concreto representado con gran fidelidad. Por otro lado, el punto de vista escogido respondía a una composición académica, de primeros planos detallados y fondos amplios, con una distribución demasiado armónica. Daba mucha importancia al dibujo, y en lo referido al color no realizaba grandes contrastes. Aún así, sus paisajes están llenos de color, luminosidad y factura rápida.

Pero no sólo la visión objetiva queda perfectamente reflejada en sus cuadros con una representación totalmente realista de la Naturaleza, sino que a esta se debe añadir la propia lectura subjetiva que de ella realiza el artista, "Y es que, este virtuoso del pincel, no sólo se adueña, al copiar la naturaleza, de sus verdaderas líneas, de sus colores y sus perspectivas, sino que lleva también a sus lienzos las múltiples transparencias del ambiente, el murmurio de los arroyos y de las fontanas, el misterioso gemido de los bosques, el aroma de las florestas y los sobrehumanos ecos de los meteoros" (Roger Vázquez, 1923, 92). Algunas de sus obras relacionadas con este lugar son Sierra del Negrete realizada en 1900 (Fig. 4) y Paisaje: Sierra del Negrete de 1909 (Fig. 5). En ambas se observa un realismo casi fotográfico, ya que se representa con total fidelidad el paisaje. Incluso se pueden diferenciar muchas de las especies vegetales que aparecen en ellas. Para conseguir esto el dibujo es muy detallado. Usa gama de colores más bien fríos; verdes para la vegetación y grisáceos para el cielo. En general, la iluminación está idealizada, no es real. Por su parte, ambas composiciones responden a criterios académicos, con unos primeros planos más detallados, en los que como hemos dicho, los elementos son identificables, y unos fondos más amplios y abiertos. En estas pinturas el artista muestra de manera magistral una visión objetiva del entorno, pero a través de su técnica, también es capaz de trasladar a ella lo que el propio paisaje le transmite.

\section{Sierra del Menejador}

La Sierra del Menejador es una alineación montañosa situada en la comarca valenciana de L'Alcoià. En su vertiente norte encontramos el Parque Natural del Carrascal de la Font Roja, concretamente, este lugar fue de los más representados. "Se cree que el nombre Font Roja viene dado por el color rojizo de estas tierras arcillosas. Sin embargo, existe otra hipótesis, que afirma que el nombre viene del latín fontis rocha, que se traduciría como la Fuente de la Roca, haciendo referencia por tanto al lugar de nacimiento del manantial" (Hernández Perelló; Gaviño Castellanos, 2013, 390). La Font Roja está situada en 


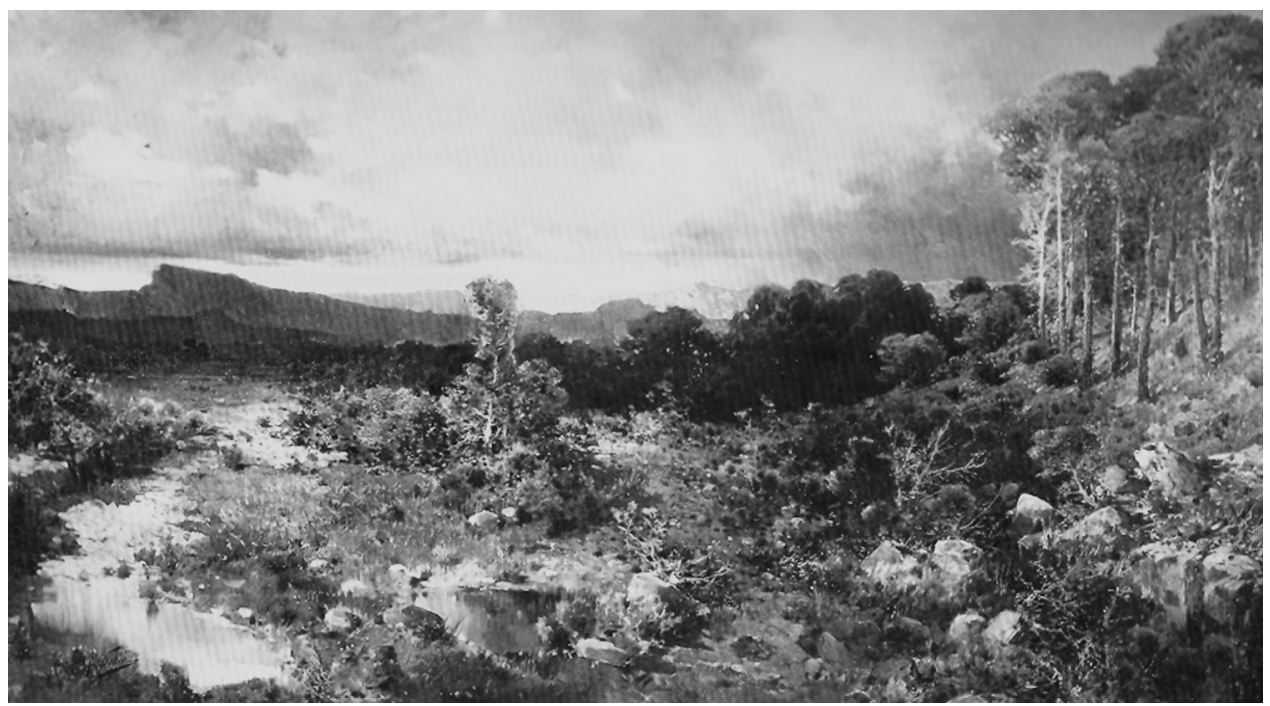

Fig. 4. Gonzalo Salvà Simbor, Sierra del Negrete, 1900. Óleo sobre lienzo, 104,8 x 168,7 cm. Museo de Bellas Artes San Pío V, Valencia.

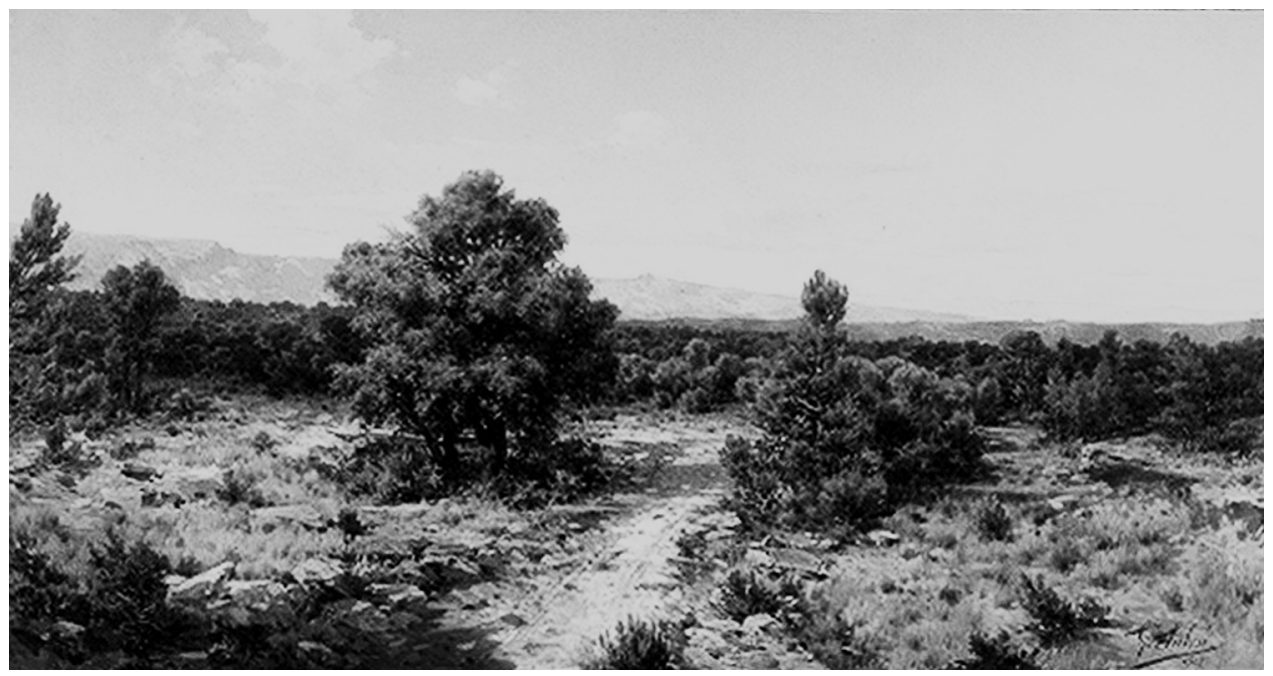

Fig. 5. Gonzalo Salvà Simbor, Paisaje: Sierra del Negrete, 1909. Óleo sobre lienzo, 105,5 x 199,8 cm. Museo de Bellas Artes San Pío V, Valencia. 
la sierra del Menejador, que se localiza entre el término municipal de Alcoy e Ibi. Este paraje tuvo una consideración muy importante a finales del siglo XIX. Desde siempre ha sido considerado como una especie de paraíso a visitar para huir de la ciudad, debido a que Alcoy, durante el siglo XIX, tuvo un importante desarrollo industrial. La población subía al carrascal, para evadirse de la contaminación fabril, de su dura realidad con condiciones laborales precarias en las que no tenían ningún derecho. En general, acudían a la Font Roja para obtener libertad, retornar a la naturaleza y respirar el aire puro ofrecido por este paraje. Además, consideraban el lugar como algo propio, con lo que se identificaban y que, a su vez, les identificaba.

Por estas razones, los artistas alcoyanos comenzaron a representar la Font Roja, ya que era un lugar que formaba parte de la tradición de la vida alcoyana. Francisco Laporta (1849-1914) realizó numerosos borradores de los alrededores del carrascal, destacando entre sus lienzos, Barranc de l'Infern. También José Mataix Monllor (1882-1952) se dedicó a pintar algunas zonas de la Font Roja, conservándose esbozos y algunas pinturas como Paisaje de la Sierra de Mariola (1901) y Barranc del Cinc (1935).

Pero, principalmente, destaca la atención que prestó Fernando Cabrera (1866-1937) a esta zona. Durante sus años de formación destacó tanto en la asignatura de Flores como en la de Paisaje, lo cual es evidente en su obra posterior ya que muestra un gran dominio de la forma y los volúmenes. Aunque comenzó a formarse dentro de las normas académicas, sufrió una importante evolución en su pintura que se hace más notoria al comienzo del nuevo siglo.

Cabrera mostró un gran interés por el paisaje que se acentuó a partir de 1920, "se enfrenta con el paisaje y vibra al contacto con la naturaleza que tanto ama" (Espí Valdés, 1970, 47). El paisaje comienza a aparecer en su producción con la obra Regreso al hogar (1888) y Junto a la fuente (1889).

En sus cuadros de paisaje Cabrera utilizó como estudio la propia naturaleza, ya que pintaba al aire libre. Puede ser considerado como el gran creador de la imaginería de paisaje de la zona alcoyana y de la Font Roja. En el año 1926, concretamente en el mes de mayo, se inauguró en Alicante una exposición individual de Fernando Cabrera en el Ateneo de Alicante. Allí mostró un total de treinta y cuatro obras, entre las que destacan los paisajes de su tierra natal, pintados en sus últimos años (Hernández Guardiola, 2005, 90).

En la producción de Cabrera encontramos toda una serie de obras sobre las inmediaciones de Alcoy, en su mayoría son imágenes de la Sierra del Menejador y, en concreto, de la Font Roja: La Calera, 1902; Paisaje de Mariola, 1925 (Fig. 6); El Alt de la Creu, 1928 (Fig. 7); Paisaje de Alcoy, 1928 (Fig. 8); Paisaje de Mariola, ca. 1928 (Fig. 9); y muchas otras de tema paisajístico. Por ejemplo en Paisaje de Alcoy, muestra su gran dominio del género paisajístico y aplica las características principales de su técnica. El color es muy importante y utiliza una rica variedad de verdes para la vegetación, azules malvas para el cielo, y tonos marrones para el terreno. Aunque el dibujo queda relegado en importancia, las formas están bien modeladas. Es interesante el contraste lumínico de luces y sombras que lleva a cabo en esta obra. La parte derecha está en penumbra, mientras que la izquierda recibe toda la iluminación. La luz solar proyecta directamente sobre el camino, y en dicha proyección quedan reflejadas las copas de los árboles sobre éste. En primer término hay un camino, al otro lado una pista forestal o un claro y al fondo la montaña. La composición es diagonal, lo cual crea una sensación de amplitud. 
Fig. 6. Fernando Cabrera Cantó, Paisaje de Mariola, 1925. Óleo sobre lienzo.
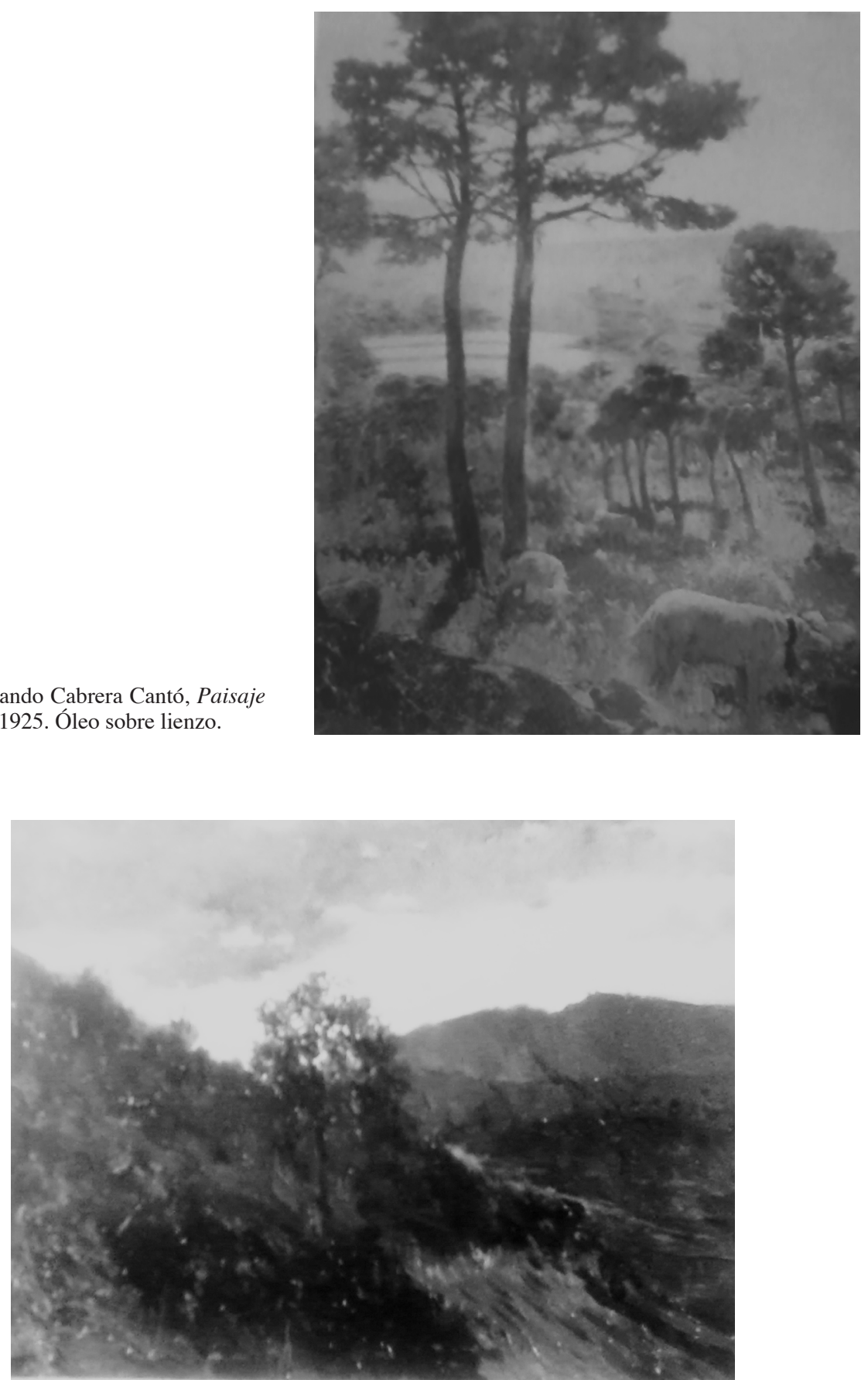

Fig. 7. Fernando Cabrera, El alt de la creu, 1928. Óleo sobre lienzo, 50 x $62 \mathrm{~cm}$. Colección Particular, Alcoy. 


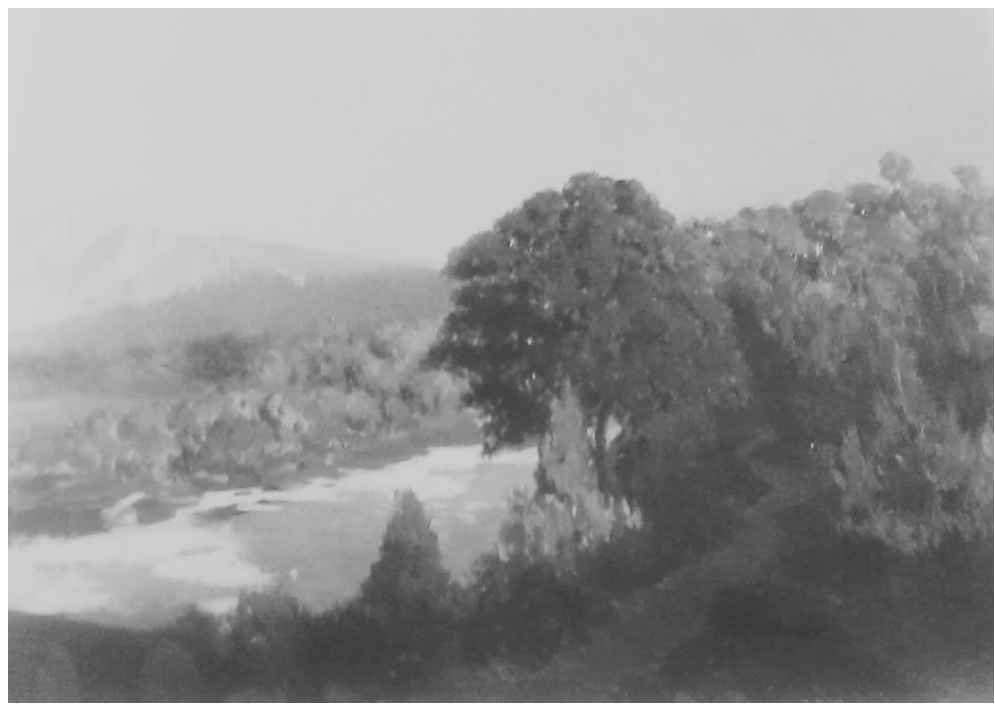

Fig. 8. Fernando Cabrera Cantó, Paisaje de Alcoy, 1928. Óleo sobre lienzo, 95 x 132,5 cm. Colección Particular, Alcoy.

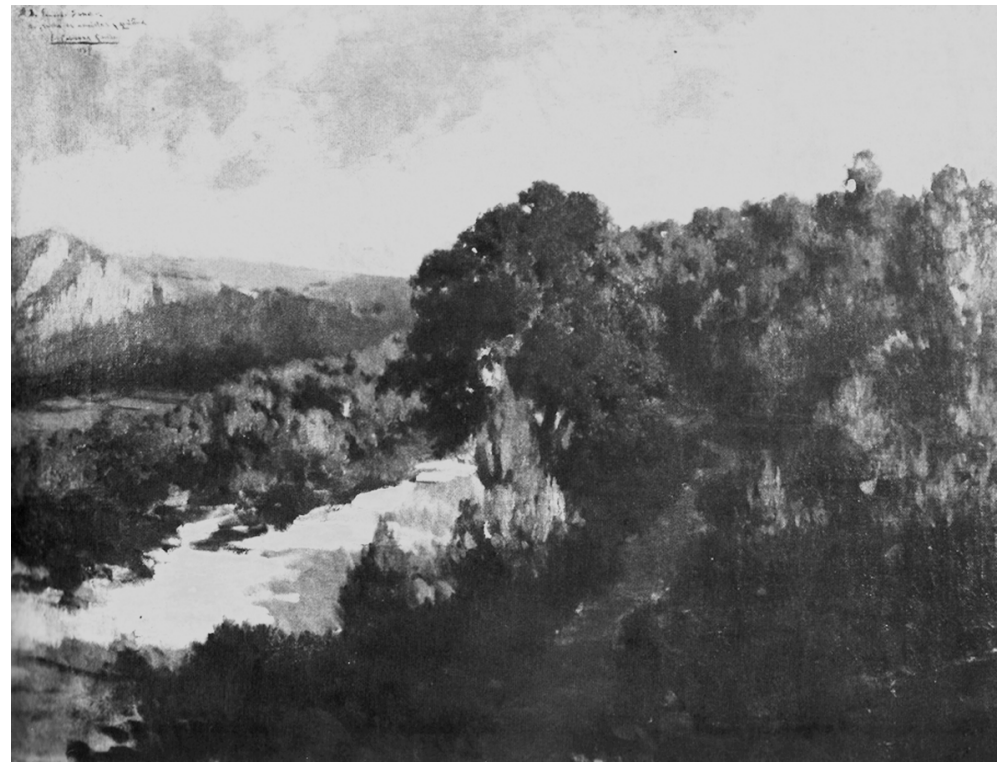

Fig. 9. Fernando Cabrera Cantó, Paisaje de Mariola, 1928. Óleo sobre lienzo, 70 x 90 cm. Colección Particular, Alcoy. 
En su obra se pueden distinguir dos etapas, una primera influenciada por su estancia romana con una pintura llamada de "argumento" y otra inclinada hacia el costumbrismo valenciano y el paisaje tras el descubrimiento de la Sierra de Mariola, Aitana, etc. todo ello bajo el luminismo sorollista, pero sin llegar a reducir a manchas la figura humana.

La actitud institucionista en la obra de Cabrera es patente en el hecho de que decide representar su entorno más cercano, aquello que le es próximo, el paisaje alicantino. Este pintor supo captar con una pincelada viva y empastación cromática las calidades atmosféricas y las estaciones del año, de forma magistral.

Finalmente, además de los lugares ya mencionados, otras montañas valencianas que también aparecerán representadas en pinturas fueron el Montdúver y el Picaio, así como el Circo de la Safor con el Desfiladero de Lorcha y la zona de túneles excavados en la roca atravesados por la línea férrea de Gandía a Alcoy.

\section{SOROLLA Y LA REPRESENTACIÓN DEL PAISAJE VALENCIANO}

No sólo la correspondencia de Francisco Giner y Manuel Bartolomé Cossío a Joaquín Sorolla conservada en el Museo Sorolla de Madrid, demuestra la estrecha relación existente entre la ILE y Sorolla, sino que ésta va más allá y se puede observar implícita en las obras del artista, concretamente, en las obras paisajísticas realizadas a partir de 1900. Sorolla era amigo de Giner y de Cossío, fundadores de la ILE, y con ellos compartía no sólo amistad sino también ideas.

En Sorolla caló una de las principales ideas institucionistas, el regeneracionismo, de ahí que prestara especial atención al paisaje como medio para cambiar la realidad española a través de su profundo conocimiento. En el año 1883 miembros de ILE recorren por primera vez la Sierra de Guadarrama. Esta salida junto con otras posteriores formará parte del objetivo de la ILE de ensalzar Castilla como símbolo de carácter español.

Otra de las principales influencias de la ILE evidente en Sorolla es el positivismo. Precisamente, una de las principales vías introductoras del positivismo en España fue la ILE. El ambiente cientifista que existía entre los círculos institucionistas (interés por las matemáticas, biología, etnología, geología, geografía) influyó en Sorolla. Muestra de ello es su gran amistad con el Doctor Luis Simarro Lacabra, quien fuera uno de los mayores representantes del positivismo en España. Sorolla siempre tuvo en cuenta la opinión y consejos de Simarro, y a través de él conoció a figuras relevantes del mundo cultural y científico de su tiempo como a los doctores Medinabeitia y Gregorio Marañón. Simarro, que estuvo vinculado a la masonería, fue un defensor de los derechos humanos, y es considerado como uno de los introductores de la psicología en España. Como señala Pérez Rojas, "Todo el importante ambiente cultural que en España se generó en torno al krausismo y la ILE llegó a Sorolla por vía de Simarro y Beruete” (Pérez Rojas, 1996, 58-59).

Sorolla supo reflejar en sus obras la época en la que vivió. No sólo tuvo relación directa con la ILE sino que además participó en la Junta para la Ampliación de Estudios, creada en 1907 bajo la influencia de la ILE. Este organismo fue suscitado por el influjo de Giner y su idea era sacar al país del retraso en el que estaba sumido, a través del conocimiento, la apertura hacia Europa y la libertad.

Aunque Sorolla es relacionado normalmente con la pintura costumbrista, es importante resaltar que dedicó gran parte de su trabajo a la pintura de paisaje. Posiblemente, sea en 
este género donde mejor se puede apreciar la evolución de su pintura, la relación que mantiene con las corrientes estéticas imperantes como el Impresionismo o los pintores escandinavos, y donde plasma toda su sensibilidad.

Sorolla se sintió muy atraído por el paisaje desde sus años de formación, ya que en la Academia había una tendencia a la pintura al aire libre. Concretamente, fue discípulo de Gonzalo Salvà Simbor en la Escuela de Bellas Artes de San Carlos, pintor que defendía entre su alumnado la pintura de paisaje al aire libre. Durante esta etapa fueron frecuentes los pequeños formatos de lugares de Valencia. Lo cual también se mantuvo durante su pensionado en Italia. Más tarde siguió experimentando con el paisaje en su etapa de consolidación, igualmente en tablitas y pequeños cartones, para desarrollarlo en lienzos a partir de 1900.

$\mathrm{Su}$ pintura de género paisajístico podría dividirse en dos grupos, los paisajes que actúan como fondo para enmarcar escenas, pero no por ello menos importantes, y los paisajes puros. Sus escenas de la vida cotidiana pintadas en años anteriores transcurren al aire libre y en ellas la naturaleza es tan protagonista como los personajes.

Pero como escribe Martínez Tussell “y (...) a partir de 1900, Sorolla viaja pintando por toda España y sus paisajes son muy sintéticos de formas, ricos de color y, sobre todo, desprovistos de anécdota. Así pinta intensamente en las dos Castillas y en Andalucía, pero esta labor como paisajista quedó un tanto eclipsada por los intensos trabajos preparatorios y la realización de las grandes pinturas de Sorolla con el tema de las regiones españolas pintadas por encargo de la Hispanic Society de Nueva York (...)" (Martínez; Tussell, 1997, 83). La mayoría de paisajes son del Norte de España (San Sebastián, Jaca), Madrid (el Guadarrama y el Pardo), Toledo y Granada (Sierra Nevada). También destacan en su producción los paisajes valencianos, sobre todo, vistas de la Malvarrosa y sus playas, aunque son de destacar, como veremos más adelante, obras que tienen como tema principal la montaña.

Por supuesto hay que considerar esta evolución y protagonismo del paisaje sorollesco en el contexto de la pintura española. Artistas como Aureliano de Beruete, dieron un nuevo rumbo y valor a este género. Si Salvà fue quien introdujo a Sorolla en el paisaje, Beruete fue quien reforzó su interés por éste.

Pero centrándonos en el tema de nuestro interés, es en la pintura de paisaje donde se evidencia la gran influencia de la ILE en Sorolla. Ésta se observa, como hemos comentado, a partir de 1900, momento en el cual el pintor comenzó a dar más importancia al paisaje. Su interés por el paisaje estaba íntimamente relacionado con el regeneracionismo propugnado por la ILE. Creían que el conocimiento del territorio llevaría a recuperar en la sociedad la conciencia nacional. Además eran conscientes del valor educativo de la naturaleza y de la necesidad del hombre de estar en contacto con ella para realizarse plenamente.

Otra impronta institucionista en la pintura de Sorolla es la dualidad. En ella se puede observar, por un lado, un carácter objetivo ya que representa lugares reales que muestran su interés cientifista, y en concreto su gusto por la geografía, todo ello relacionado como hemos visto con el krausopositivismo de la ILE. Y por otro, un carácter subjetivo, ya que es en sus paisajes donde mejor se percibe la sensibilidad del artista, su ternura, su capacidad de conmoverse, en líneas generales, su humanidad.

Aunque Sorolla pintó diversidad de paisajes, prestó especial atención a la montaña. Representó especialmente la Sierra de Guadarrama, lugar predilecto de la ILE. Fue dicha institución la que redescubrió esta sierra hasta entonces casi desconocida para los madrileños a través del excursionismo, otorgándole un valor no sólo ético sino también estético. 
Pero sus representaciones montañosas no sólo se quedaron en la Sierra de Guadarrama, sino que también pintó El Pardo, y zonas montañosas de Asturias, San Sebastián, Guipúzcoa, Jaca, Canfrac, Sierra Nevada y también de Nápoles y Asís.

Para realizar sus paisajes practicaba el excursionismo llevado a cabo por la ILE. Sorolla pasaba el invierno en el estudio, pero el resto del año lo aprovechaba para viajar, salir al aire libre, recorrer los lugares que seleccionaba y realizar sus pinturas. Es precisamente en esta pintura al aire libre donde muestra una técnica más fresca, rápida y en la que demuestra sus buenas dotes de captación y espontaneidad.

Sin duda, donde mejor se observa el gusto de Sorolla por el paisaje es en sus apuntes. En estas pequeñas notas de color se compendia todo lo comentado anteriormente, tanto a nivel conceptual como formal. Pero por el tema de nuestro trabajo, hemos seleccionado aquellos en los que representa paisajes montañosos localizados en la zona valenciana. Es el caso de Paisaje de Valencia (1889) (Fig. 10), Paisaje valenciano (1889) (Fig. 11), y Paisaje valenciano (1889-1890) (Fig. 12). Pero también hay lienzos en los que la montaña, sigue teniendo un gran protagonismo, éste es el caso de Naranjos, Alzira (1908) (Fig. 13). En esta última, de nuevo Sorolla pintó una zona del interior valenciano, concretamente la zona montañosa de Alcira. Desde un jardín representado en primer plano, se observan varios huertos de naranjos recortados sobre grandes montañas grisáceas al fondo. Por último aparece el cielo, con nubes rosadas, aunque en este caso la representación se reduce a una estrecha franja. En la mitad inferior, que coincide con la tapia del jardín y los árboles, la pincelada es más compacta y detallada, mientras que en la mitad superior, y sobre todo en las montañas, la pincelada es mucho más suelta.

En conclusión, Sorolla en sus obras de paisaje se centró en la idea de Giner de entender el paisaje como medio de conocimiento y de profundización para el cambio de la realidad española, pero siempre a través de unos procedimientos basados en un método reformista y pausado.

\section{CONCLUSIONES}

A finales del siglo XIX la influencia de la Institución Libre de Enseñanza, llegó a Valencia y penetró en la zona a través de diversos intelectuales que, tras formarse en Madrid, desempeñaron su labor profesional en la región valenciana. En un primer momento el institucionismo valenciano comenzó a darse de forma más notoria en el ámbito universitario, pero posteriormente llegó a otras esferas de la sociedad como la jurídica y cultural.

Los preceptos institucionistas, como la nueva visión que tenían de la naturaleza, que es lo que a nosotros nos interesa, comenzó a arraigar debido, en gran medida, a la creación de centros (Escuela de Artesanos, Institución para la Enseñanza de la Mujer, etc.), con clara influencia de la ILE, que permiten llevar a cabo las ideas que dicha institución preconizaba.

Como ya hemos visto anteriormente, a nivel cultural, la influencia de la ILE en Valencia, en cuanto a lo que a la nueva visión de la naturaleza se refiere, se tradujo en la realización de estudios geográficos, interés por el excursionismo, auge de la literatura de viajes y desarrollo de la pintura de paisaje.

A finales del siglo XIX, se produjo un importante desarrollo de este género que llegará incluso hasta las primeras décadas del siglo siguiente. Este interés por el paisaje también despertó en artistas que no se dedicaban específicamente a este género como Joaquín Agrasot. 


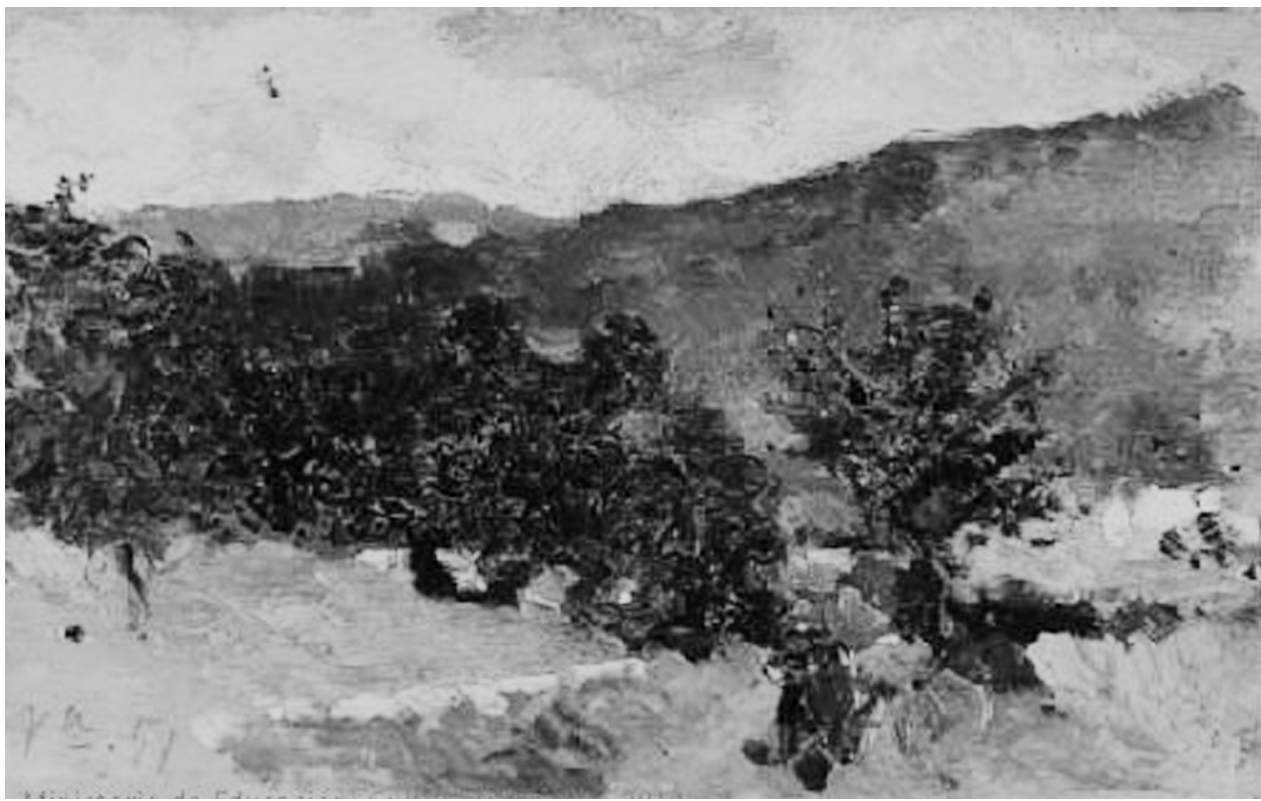

Fig. 10. Joaquín Sorolla y Bastida, Paisaje de Valencia, 1889. Óleo sobre tabla, 8,80 x 13,60 cm. Museo Sorolla, Madrid.

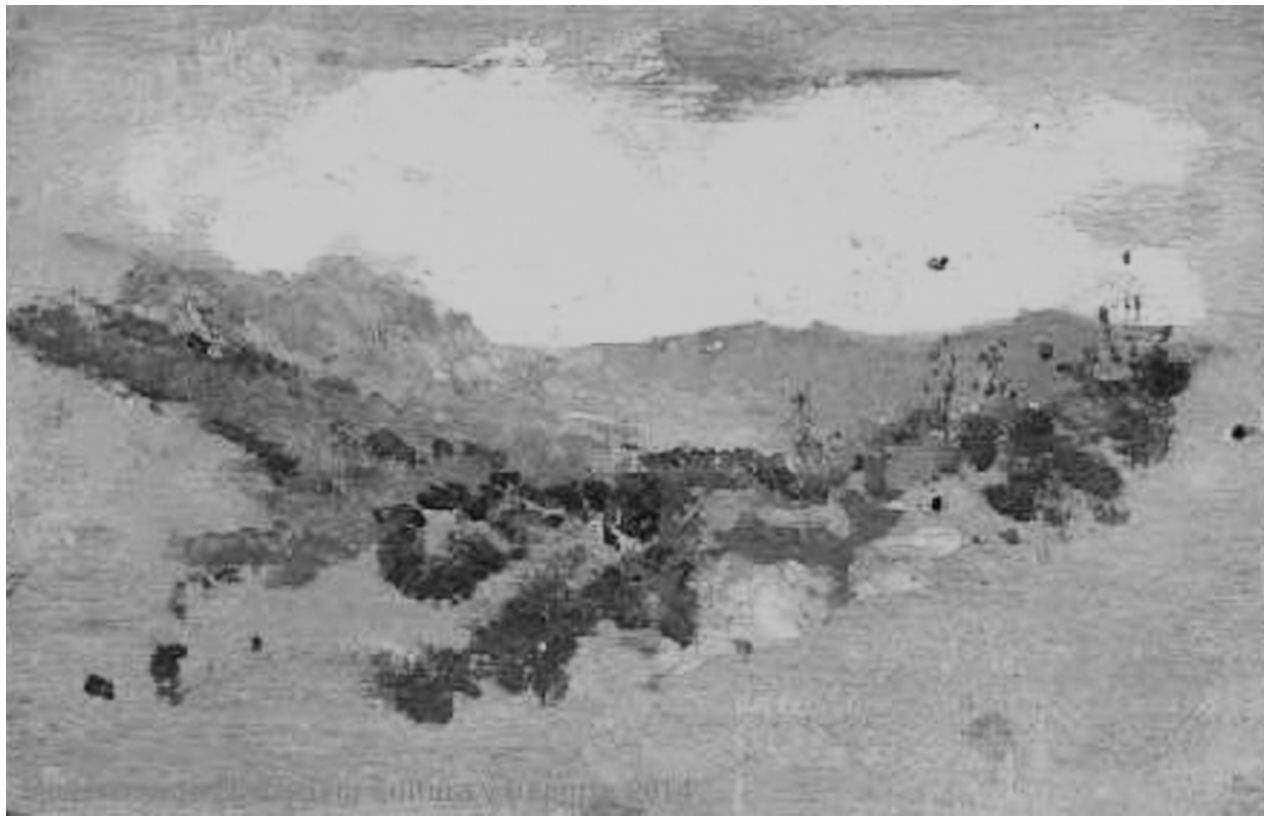

Fig. 11. Joaquín Sorolla y Bastida, Paisaje valenciano, 1889. Óleo sobre tabla, 8,80 x 13,60 cm. Museo Sorolla, Madrid. 


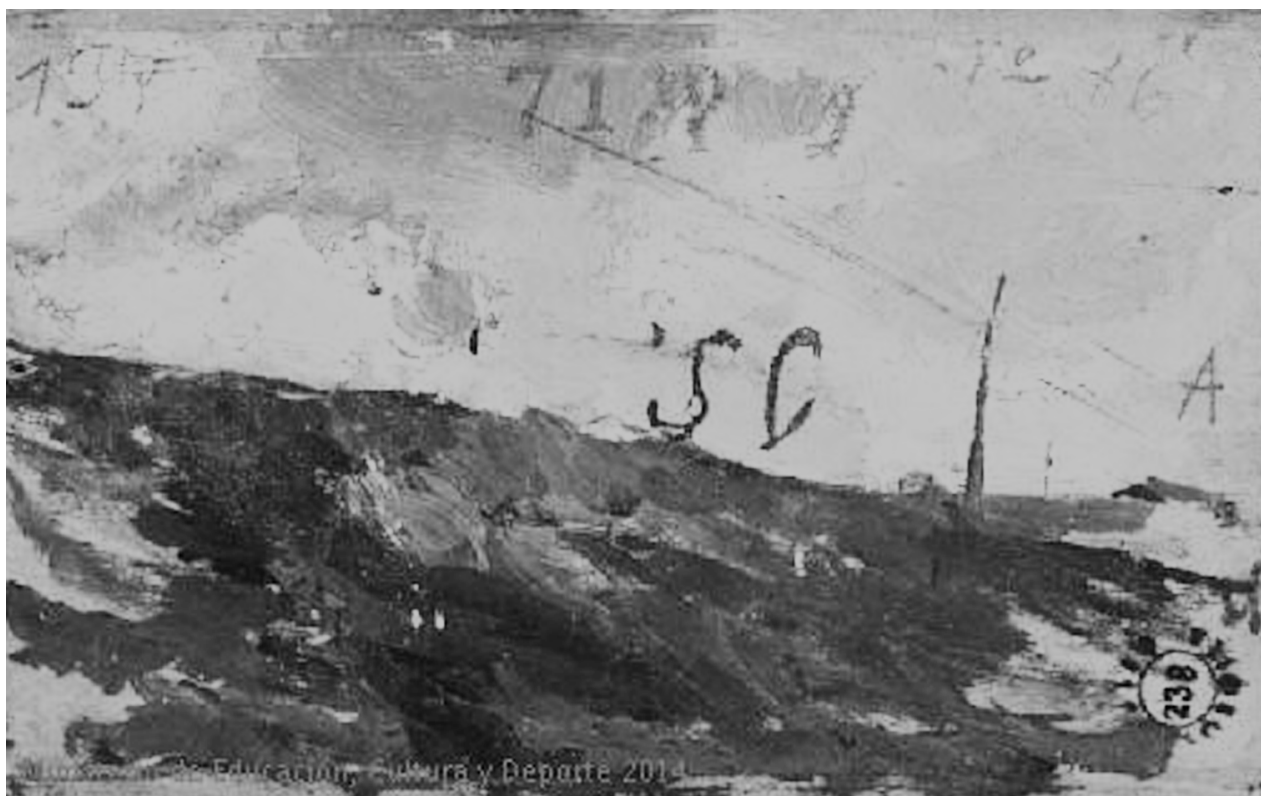

Fig. 12. Joaquín Sorolla y Bastida, Paisaje valenciano, 1880-1890. Óleo sobre tabla, 8,80 x $13,70 \mathrm{~cm}$. Museo Sorolla, Madrid.

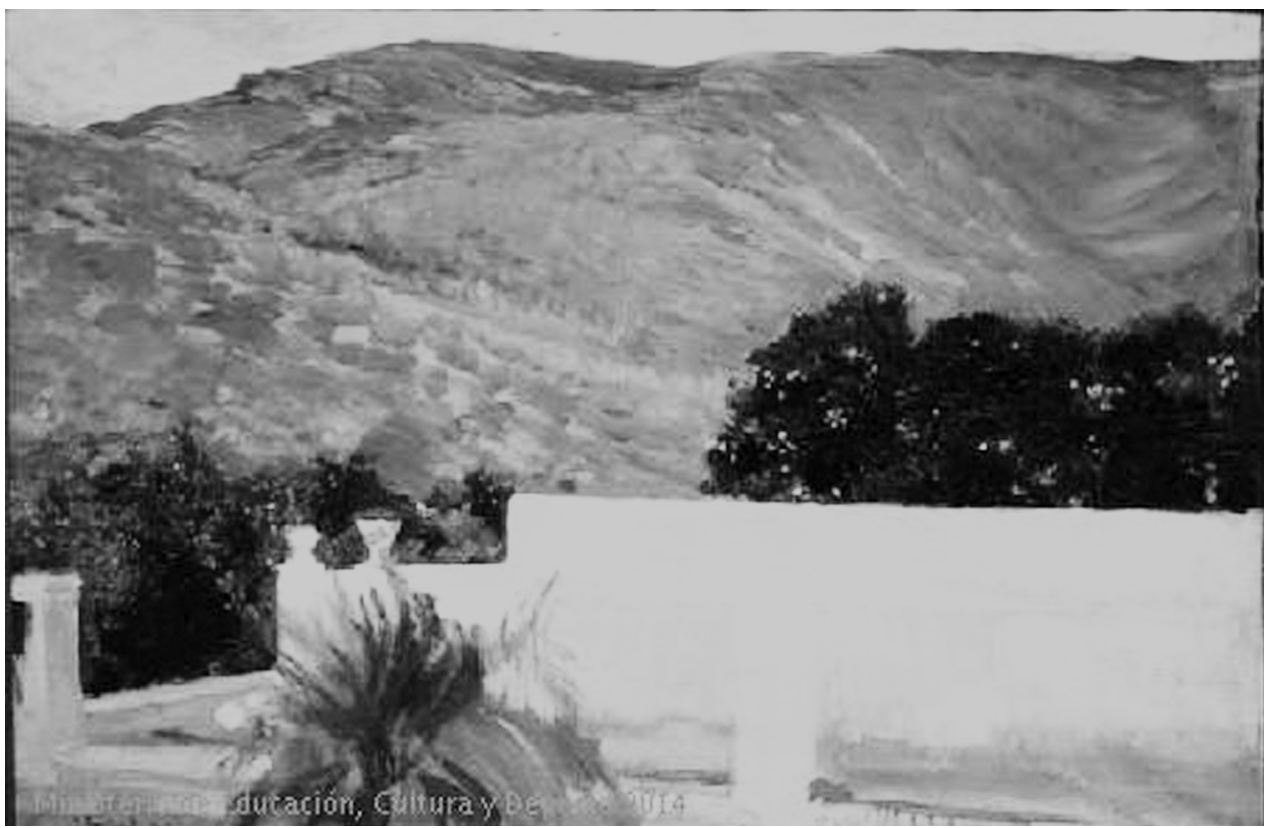

Fig. 13. Joaquín Sorolla y Bastida, Naranjos, Alcira, 1908. Óleo sobre lienzo, 65 x 97 cm. Museo Sorolla, Madrid. 
Pero dicho desarrollo no sólo se debió a la influencia ejercida por el círculo de pintores pertenecientes a la Real Academia de Bellas Artes San Fernando de Madrid con Carlos de Haes a la cabeza, sino también a la llegada del institucionismo a Valencia y a su influencia en diversos ámbitos de la sociedad valenciana. A nivel nacional fue Carlos de Haes el que renovó la pintura de paisaje, y es su influencia la que hace que en la zona valenciana surja interés por el género paisajístico, pero fue gracias al influjo de la ILE por lo que la pintura valenciana de paisaje experimentó un importante desarrollo.

La relación de la ILE con el mundo artístico valenciano llegó desde dos puntos, por un lado, muchos artistas y pintores del momento se formaron en centros de cariz institucionista como la Escuela de Artesanos y por otro lado, está el hecho de que la mayor parte de las exposiciones de Bellas Artes llevadas a cabo en Valencia eran patrocinadas por instituciones también muy relacionadas con el institucionismo como el Ateneo o la Real Sociedad Económica de Amigos del País de Valencia.

En la pintura valenciana de paisaje también quedan implícitos los preceptos promulgados por la ILE en relación a la naturaleza. En primer lugar, el interés por la naturaleza es ya un claro aspecto institucionista (que le viene a la ILE del krausismo y del positivismo), pero además se acentúa porque es un interés por la naturaleza del entorno, por los paisajes que conocen. El lugar representado era totalmente identificable y conocido por el espectador. Además cada uno de los elementos que lo conforman también se podía identificar (vegetación, árboles, montañas, etc.). Relacionado con esto está la práctica de excursiones. Los pintores valencianos visitaban y pintaban muchos de los paisajes que los institucionistas valencianos visitaban, como es el caso de Soler que visitaba Porta Coeli, y para los pintores se convirtió en un lugar apreciado que representar.

Otra cuestión en común con la ILE es la dualidad con la que representaban en sus obras la naturaleza, es decir, por un lado tienen una visión objetiva que se refleja en el traslado fiel de lo que ven al lienzo, y por otro lado en las obras se observa cierto carácter subjetivo. Esa subjetividad radica en que el artista tiene por sí mismo la capacidad para elegir los lugares que quieren representar y de qué manera, por lo que su punto de vista es fundamental en la obra de arte, no sólo por sus elecciones sino por su visión individualizada de la naturaleza. Es decir, el artista traslada a la pintura parte de sí mismo, y lo hace a través del lugar seleccionado, los colores utilizados, etc. Todo ello con la intención de proyectar su "yo" a la obra. Por último, el interés por un tipo de paisaje montañoso. Pudiendo elegir otros tipos paisajísticos hay artistas que se centran en este, que es precisamente por el que más se interesó la ILE.

Desde este punto de vista, en cuanto a la pintura de paisaje valenciana del siglo XIX se refiere, deberemos pues rastrear, no sólo lo universal del mismo, sino lo diferencial en su historia, marcada por un territorio cultural periférico muy específico. Por tanto, en la renovación del paisaje valenciano del fin de siglo pueden considerarse personalidades de primer orden a Antonio Muñoz Degrain y Sorolla, sin por ello olvidar la aportación de otros autores como Emilio Sala, Cecilio Pla, Constantino Gómez o incluso Manuel Benedito que concurren y coinciden en ese momento decisivo del tránsito del siglo XIX al XX. Todos ellos cultivan otros géneros pero el paisaje tiene un valor en sí o impone su presencia en otras temáticas.

En los años 90, el paisaje avanza con intensidad hacia la captación de otras realidades, interesándose por el mundo de la huerta con sus tipos y costumbres, reflejando esa cotidianeidad. La geografía valenciana entró a formar parte del repertorio de los paisajistas 
del mismo modo que sucedería en el resto del país, y en este sentido Valencia se hallaba en sintonía con el desarrollo artístico nacional.

Finalmente, sólo cabe decir, que con este trabajo hemos intentado arrojar más luz a la valoración patrimonial y simbólica del paisaje valenciano, en concreto, por parte de varios pintores en la región, que no sólo comenzaron a conocer mejor la naturaleza que les envolvía sino que también empezaron a conocerse mejor a ellos mismos, y lo que eran por haber vivido en ese lugar.

\section{BIBLIOGRAFÍA}

AA.VV. (2001): El valle de la Murta y su monasterio, Valencia, Ayuntamiento de Alzira, 77 p.

ALCAHALÍ, BARÓN DE (1989): Diccionario biográfico de artistas valencianos, Valencia, Librerías París Valencia, 443 p.

BONET SOLVES, VICTORIA (1988): Pintura de paisaje en el siglo XIX valenciano (tesis de licenciatura), Valencia, Universitat de València, 314 p.

BONET SOLVES, VICTORIA (1989): "Gonzalo Salvà Simbor, introductor del paisaje de la realidad en Valencia", Archivo de Arte Valenciano, 70, 89-92.

BONET SOLVES, VICTORIA (1989): "Paisaje de la realidad en la pintura de valenciana del siglo XIX”, Boletín de Arte, 10, 317-322.

BONET SOLVES, VICTORIA (1994): “Antonio Muñoz Degrain o la fascinación del color”, Saitabi: Revista de la Facultat de Geografia i Història, 44, 255-266.

BONET SOLVES, VICTORIA (1995): "Los temas de la pintura de paisaje del siglo XIX en Valencia”, Saitabi: Revista de la Facultat de Geografía i Història, 45, 69-78.

DELICADO MARTÍNEZ, JAVIER; BALLESTER HERNÁN, CAROLINA (1999): "El Monasterio Jerónimo de Santa María de la Murta, de Alzira, tras de las desamortizaciones del siglo XIX. La dispersión y pérdida de su legado artístico y cultural", Archivo de Arte Valenciano, 80, 80-90.

ESPÍ VALDÉS, ADRIÀ (1970): Itinerario por la vida y la pintura de Fernando Cabrera y Cantó (Apuntes para una biografía del maestro), Alicante, Instituto de Estudios Alicantino: Diputación Provincial de Alicante, $156 \mathrm{p}$.

ESTEBAN MATEO, LEÓN (1974): La Institución Libre de Enseñanza en Valencia (Institucionistas valencianos), Valencia, Editorial Bonaire, 285 p.

GRACIA BENEYTO, CARMEN (2001): La imagen del pensamiento: el paisaje en Ignacio Pinazo (exposición), Valencia, Bancaixa, 221 p.

HERNÁNDEZ GUARDIOLA, LORENZO (2005): Fernando Cabrera Cantó, Alicante, Diputación de Alicante, $261 \mathrm{p}$.

HERNÁNDEZ PERELLÓ, MARI CARMEN (2015): La influencia de las teorías de la Institución Libre de Enseñanza sobre estética y naturaleza en la pintura valenciana de paisaje (tesis doctoral), Valencia: Universitat de València. Facultat de Geografia i Història, 744 p.

HERNÁNDEZ PERELLÓ, MARI CARMEN; GAVIÑO CASTELLANOS, PABLO (2013): "La visión cultural de la Font Roja de Alcoy: Un reflejo del entendimiento romántico de la naturaleza", Pasos: Revista de Turismo y Patrimonio Cultural, vol. 11, 2, 387-398.

LÓPEZ ALBERT, SUSANA (1998): "Muñoz Degrain pintor de la luz", Archivo de Arte Valenciano, 79,134-139

LÓPEZ ALBERT, SUSANA (2006): Una nueva visión de la pintura valenciana: los elementos botánicos y el paisaje, Valencia: Universitat de València. Departament d' Història de l' art, 380 p.

LÓPEZ ALBERT, SUSANA (2007): "El árbol. Protagonista del paisaje de fin de siglo", Saitabi: Revista de la Facultat de Geografia i Història, 57, 149-168. 
LÓPEZ ALBERT, SUSANA (2008): "Entre valles y monasterios: El paisaje valenciano a finales del siglo XIX", Ars Longa, 17, 105-115.

MARTÍNEZ NOVILLO, ÁLVARO; TUSSELL, JAVIER: Paisaje y figura del 98, Madrid, Fundación Central Hispano, 1997, 236 p.

ORTEGA CANTERO, NICOLÁS (1986): "La Institución Libre de Enseñanza y el entendimiento del paisaje madrileño", Anales de la Geografía de la Universidad Complutense, 6, 81-98.

PANTORBA, BERNARDINO DE (1970): La vida y obra de Joaquín Sorolla, Madrid, Extensa, $227 \mathrm{p}$.

PENA LÓPEZ, MARÍA DEL CARMEN (1998): Pintura de paisaje e ideología: la generación del 98, Madrid, Taurus, $140 \mathrm{p}$.

PÉREZ ROJAS, FRANCISCO JAVIER (1996): Los Sorolla de Valencia (exposición), Bass Museum of Art, Valencia, Generalitat Valenciana, $221 \mathrm{p}$.

PÉREZ ROJAS, FRANCISCO JAVIER (1998): Tipos y paisajes (exposición 1890-1930: Valencia, Museo de Bellas Artes, del 3 de diciembre de 1998 al 17 de enero de 1999, comisario Francisco Javier Pérez Rojas), Valencia, Consorci de Museus de la Comunitat Valenciana, 530 p.

ROGER VÁZQUEZ, G (1923): "Gonzalo Salva Simbor", Archivo de Arte Valenciano, 9, 91-94.

ROIG CONDOMINA, VICENTE (1994): Las Exposiciones de Bellas Artes en la Valencia del siglo XIX (tesis doctoral), Valencia, Universitat de València. Departament d' Història de l'Art, 1000 p.

ROIG CONDOMINA, VICENTE (1996-1997): "Algunes notes sobre els inicis del Cercle de Belles Arts de València i la seua activitat en el segle XIX”, Ars Longa: Cuadernos de Arte, 7-8, 239-245.

SANTA ANA, FLORENCIO DE (2002): Sorolla paisajista (exposición), Valencia, Instituto Portuario de Estudios y Cooperación: Autoridad Portuaria de Valencia, 167 p.

SAURET, TERESA (2007): Muñoz Degrain y las poéticas paisajísticas fin de siglo en Málaga (10 de diciembre de 2007 al 30 de marzo de 2008), Málaga, MUPAM (Museo de Patrimonio Municipal), $121 \mathrm{p}$.

SEMPERE VILAPLANA, LUISA (2000): "La colección de pinturas y dibujos de las escuelas de artesanos de Valencia", Ars Longa: Cuadernos de Arte, 9-10, 313-320.

TORRES GONZÁLEZ, BEGOÑA (2005): Sorolla: la magia de la luz, Madrid, Libsa, 400 p. 